\title{
Secondary tumours in Sjögren's syndrome
}

\author{
László Kovács $^{\mathrm{a}, *}$, Peter Szodoray ${ }^{\mathrm{b}}$, Emese Kiss ${ }^{\mathrm{c}}$ \\ a Department of Rheumatology, Albert Szent-Györgyi Clinical Centre, University of Szeged, Hungary \\ b Institute of Basic Medical Sciences, Immunobiological Laboratory, University of Oslo, Norway \\ c Department of Clinical Immunology and Rheumatology, National Institute of Rheumatology and Physiotherapy, Budapest, Hungary
}

\section{A R T I C L E I N F O}

\section{Article history:}

Received 1 July 2009

Accepted 7 July 2009

Available online 12 July 2009

\section{Keywords:}

Sjögren's syndrome

Lymphoma

Marginal zone B cell

Activation-induced cytidin-deaminase

B-lymphocyte activating factor

Chemokine

\begin{abstract}
A B S T R A C T
The frequent association of Sjögren's syndrome (SS) with non-Hodgkin's B cell lymphoma (NHL) provides an example of the interplay of systemic autoimmunity and lymphoproliferative diseases, and an opportunity to study the pathogenetic steps of lymphomagenesis. NHL develops in approximately 5\% of SS patients. Parotidomegaly, lymphadenopathy, inflammatory neuropathy and vasculitis have been found to be predictive of the development of lymphoma. A subsequent NHL is also heralded by the appearance of cryoglobulinaemia and serum or urinary monoclonal proteins. The typical histological type of NHL in SS is a low-grade extranodal marginal zone B cell lymphoma. The authors discuss the proposed key immunopathologic steps of lymphomagenesis in SS in detail. Recent results indicating the pathogenetic role of ectopic germinal centre formation in the involved exocrine glands, the potential importance of an antigen-driven clonal proliferation of autoreactive B-lymphocytes, the proposed role of the B-lymphocyte activating factor (BAFF) and of further cytokines and, finally, the changes of the chemokine milieu at the site of lymphoma development are highlighted.
\end{abstract}

(c) 2009 Elsevier B.V. All rights reserved.

\section{Contents}

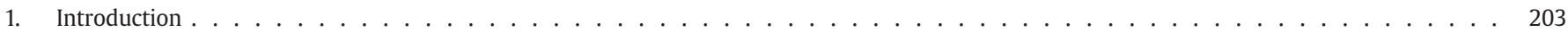

2. Clinical presentation of $\mathrm{NHL}$ in $\mathrm{SS} \ldots \ldots \ldots \ldots$

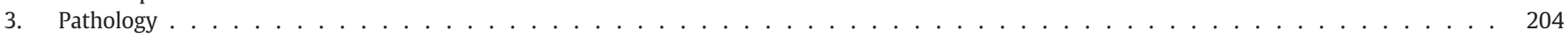

4. The cellular basis of lymphomagenesis-from benign lymphoproliferation to malignancy . . . . . . . . . . . . . . . . . . . . . . . . . 204

5. Summary . . . . . . . . . . . . . . . . . . . . . . . . . . . . . . . 205

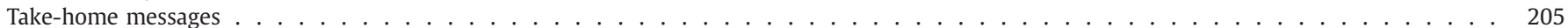

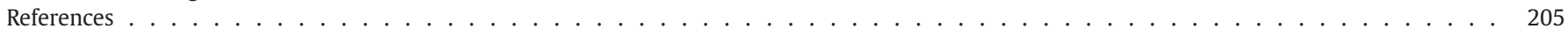

\section{Introduction}

The only malignancy, having a proven association with Sjögren's syndrome (SS) is non-Hodgkin's lymphoma (NHL) [1]. Nevertheless, this link between SS and NHL is one of the strongest among all the known associations between systemic autoimmune diseases and malignancies. The occurrence of NHL has been reported to be as much as 44 -fold greater than in the general population [2]. Subsequent surveys also confirmed a clearly increased risk of lymphomagenesis in SS, although with somewhat lower standardized incidence ratios ranging from 8.7 to $33.3[3,4]$ and of 6.6 in the most recently published series [5].

\footnotetext{
* Corresponding author. Kálvária sgt. 57, H-6725 Szeged. Tel./fax: +36 62561332. E-mail address: kovl@in1st.szote.u-szeged.hu (L. Kovács).
}

\section{Clinical presentation of NHL in SS}

The prevalence of NHL was found to be $4.3 \%$ in SS in a large multicentre European study [6]. Other studies revealed similar occurrence rates [7,8]. Lymphoma development is typically a late event during the course of SS with reported median SS disease durations ranging from 7.5 to 14 years before the diagnosis of lymphoma [6,8,9]. A number of clinical factors have been identified which occur more frequently in SS patients, who subsequently develop NHL than in SS patients in general. These include lymphadenopathy $[6,8]$, parotid gland enlargement $[2,6,8]$, inflammatory neuropathy [6], and vasculitis [6,8] (including purpura) [5]. Laboratory findings which appear to be predictive of lymphoma development are low serum complement-4 (C4) levels [5,6,10], mixed monoclonal cryoglobulinaemia (type II cryoglobulinaemia) [6,11]; the latter being usually associated with the presence of monoclonal immunoglobulin in the serum [11], or free light chain in the urine [8]. Although, all of the abovementioned signs can be found in SS patients with no evidence of 
lymphoma, patients with these features need thorough follow-up with respect to the presence or the subsequent development of NHL.

\section{Pathology}

In the majority of patients, the histopathologic type of lymphoma is mucosa-associated lymphoid tissue (MALT) type B cell lymphoma, i.e. extranodal marginal zone B cell lymphoma. In about $30 \%$ of SS patients, other types of NHL can be observed, in particular, diffuse large B cell lymphoma (DLBCL), follicle centre lymphoma and lymphoplasmocytoid cell lymphoma [5-7]. Overall, the MALT lymphoma cases typically present with a low-grade histological morphology and a relatively benign clinical course, while about one-third of the patients develop an intermediate- or high-grade lymphoma, including DLBCL [6,11]. The origin of NHL is extranodal in approximately $80-85 \%$ of the patients, with the parotid gland being the most frequent site $[6,9]$. Other mucosal sites including the stomach, lung, genital mucosa or pharynx are also common.

In the MALT lymphoma subtype, the proliferating cells are CD20+/ IgD-/Bcl-2+ B-lymphocytes, with monocyte-like morphology and high mitotic activity, pale nuclei and evident nucleoli, consistent with the marginal zone B cell appearance [9,12]. In the salivary glands, these cells diffusely infiltrate the parenchyma, forming dense sheets of proliferating cells, often destroying and subverting the glandular structure. In extranodal sites, the lymphomatous expansion of B cells always arises in the proximity of ectopic germinal centre-like structures, a peculiar phenomenon reported to evolve in approximately $20-30 \%$ of the SS patients [12,13].

\section{The cellular basis of lymphomagenesis-from benign lymphoproliferation to malignancy}

In SS, the predominant cellular components of the focal lymphocytic infiltration in the salivary glands are CD4+ T lymphocytes. The evolution of a malignant proliferation of B-lymphocytes from this inflammatory infiltration is certainly a complex and multi-step process. The ultimate step in this process is the transition from benign $B$ cell proliferation to malignant expansion. The uncontrolled expansion of B-lymphocytes is a result of various genetic alterations, typically translocations involving immunoglobulin gene loci and proto-oncogenes or other genes involved in cell-cycle regulation. As an example of the several genetic transformations associated with lymphomagenesis in general, translocations involving the MALT1 gene $t(11 ; 18)(\mathrm{q} 21 ; \mathrm{q} 21)$ and $\mathrm{t}(14 ; 18)(\mathrm{q} 32 ; \mathrm{q} 21)$ are considered as genetic events specific for MALT lymphoma. These translocations have been found in only relatively small proportions of $26 \%$ and $15 \%$, respectively, in SS MALT lymphoma patients [14]. Novel mutations in the p53 tumour-suppressor gene have been detected in 2 of $5 \mathrm{SS}$ low-grade lymphoma samples, and its pathogenetic significance has been proposed [15]. However, consistent molecular abnormalities relating to lymphomagenesis in SS have not yet been conclusively identified. As the possibility of an aberrant genetic event increases with the number of cell divisions and with the intensity of the processes involving immunoglobulin affinity maturation and class switch recombination, the role of SS-specific immunological processes and characteristics of the local glandular microenvironment driving the perpetuated B-lymphocyte proliferation need particular attention. The observation by Streubel et al. that the classical $t(11 ; 18)(\mathrm{q} 21 ; \mathrm{q} 21)$ translocation was detected in only 1 of 17 SS patients (6\%) with extragastrointestinal lymphoma, as opposed to 6 of 9 SS patients (67\%) with gastric MALT lymphoma further underlines the role of potential pathogenetic factors in the salivary gland.

Labial salivary gland and parotid gland histological examinations indicate a wide spectrum in the degree of lymphocytic infiltration ranging from scattered perivascular lymphocytes to the diagnostic hallmark of focal periductal lymphocytic infiltrates, containing B-lymphocytes, macrophages and dendritic cells in addition to the predominant CD4+ $\mathrm{T}$ lymphocytes [12]. The increasing histologic score is not only a quantitative phenomenon; more intense infiltration is also associated with increasing proportions of B-lymphocytes, a more pronounced segregation of $\mathrm{T}$ and $\mathrm{B}$ cell compartments, and finally, the formation of ectopic germinal centre-like structures resembling secondary follicles in lymphoid organs, characterised by the presence of follicular dendritic cell networks and high-endothelial venules. Several studies emphasize the importance of ectopic germinal centre formation, concluding that this is a sine qua non of NHL formation [12,13].

Malignant B cell clones arise as a result of an antigen-driven process in these germinal centre-like structures. Analysis of these clones from various patients has revealed a strikingly restricted repertoire of immunoglobulin (Ig) heavy and light chain gene usage [16]. The malignant marginal zone B-lymphocytes express hypermutated, class-switched Ig-s indicating a positive selection from the B cell repertoire probably involving $\mathrm{T}$ cell help [17]. Ig-s expressed by the majority of the clonally expanding marginal zone B-lymphocytes have rheumatoid factor properties, and it is feasible to hypothesise that locally present Ig-s or (auto)antibody-containing immune-complexes act as constant stimulators of the B cell receptors of these cells. However, the antigen specificity of the malignant B-lymphocytes has not been clarified yet. It was also demonstrated that activationinduced cytidin-deaminase (AID), the enzyme responsible for somatic hypermutation in the Ig genes during the affinity maturation of B cells, is expressed in SS salivary glands, notably exclusively in the germinal centre-like structures [12]. This finding further supports the presence of an antigen-driven clonal B cell proliferation in SS salivary glands.

A potential player in SS lymphomagenesis is presumably the B-lymphocyte activator of the TNF-family (BAFF), a potent inducer and perpetuating factor of B-lymphocyte activation and proliferation [18]. It is highly up-regulated in several autoimmune diseases, with increased mean serum levels in SS, even higher than in SLE or RA [19]. BAFF has been found to be over-expressed in SS salivary glands, particularly by glandular epithelial cells and infiltrating T lymphocytes [20]; serum levels of BAFF have been shown to be correlated with the focus score of the minor salivary gland infiltrates [21], and with germinal centre formation [22]. Furthermore, BAFF-transgenic mice develop a SS-like disease characterised by salivary gland focal lymphocytic infiltrations, notably with a predominance of B-lymphocytes of the marginal zone $\mathrm{B}$ cell phenotype [19]. BAFF has been shown to have a key role in malignant B cell survival, moreover BAFF-production correlated with the histological grade and patient survival in a study on NHL patients [23]. Lymphocytes infiltrating the salivary gland have been found to have an impaired ability to commit to apoptosis [24]. This defect seems to be related to the increased expression of the anti-apoptotic mediator of Bcl-2. Interestingly, one mechanism whereby BAFF leads to excess B cell survival is the induction of Bcl-2 [23]. Furthermore, BAFF has also been implicated in lymphoma development in chronic hepatitis $C$ virus infection, a process showing many similarities with the lymphomagenesis in SS, including the strong predictive potential of mixed cryoglobulinaemia [25-28]. Finally, BAFF was demonstrated to up-regulate AID, and promote class switch recombination in human B-lymphocytes via the activation of p38 MAPK [29]. Taken together, these observations strongly suggest that BAFF is a realistic candidate contributor to lymphomagenesis in SS with potential therapeutic implications either as a target, or as a prognostic factor. In this context, Quartuccio et al. have presented a case with SS and lymphoma, where serum BAFF levels appeared to correlate with the therapeutic response to rituximab and prednisolone [30-32]. However, further evidences with regard to BAFF and lymphoma evolution in SS are required.

An interesting observation sheds light on further potential cytokine interactions at the site of active $B$ cell proliferation. As mentioned above, BAFF-transgenic mice have a strong tendency to develop lymphocytic sialadenitis reminiscent of SS [19]. BAFF-transgenic mice lacking tumour necrosis factor- $\alpha$ (TNF- $\alpha$ )-while developing a disease similar to TNF- $\alpha$ producing mice-demonstrated a strikingly increased susceptibility to MALT lymphoma development [33]. On the other hand, BAFF has been 
shown to increase IL-10 production [34], and the over-expression and extensive local production of IL-10 has been speculated to be associated with B-lymphocyte hyperactivity and lymphoma development $[35,36]$ although formal proofs have not been presented. A detailed examination of the Th1/Th2 balance in lymphocytes infiltrating the salivary glands concluded that this cytokine balance may change with time during the evolution of SS [37]. Although the precise role of the particular cytokines in SS has not been fully understood, emerging data suggest a significant contribution of the local cytokine milieu to lymphoma development, and these observations may lead to therapeutically relevant conclusions.

A striking redistribution of B-lymphocytes in SS patients has been described by Hansen et al. [38]. In this study, a significant reduction of CD27+ memory B cells was found in the circulation, in contrast with increased numbers in the parotid gland; moreover, memory Blymphocytes in the salivary gland exhibited a higher Ig $V_{H}$ gene mutational frequency. This finding is in contrast with data from patients with SLE, where increased numbers of CD27+ memory B cells and CD27 ${ }^{\text {high }}$ plasma cells are associated with increased disease activity [39]. The findings in SS are consistent with an accumulation of memory B cells in the target glands. In this context, an abundant expression of two chemokines, CXCL13 and CCL21 was observed in SS salivary glands; these two B cell attracting chemokines are considered crucial in the formation of lymphoid tissue, including ectopic germinal centres [40]. Notably, CXCL13 and CCL21 expression was found only in areas of benign lymphoepithelial lesions, and was abandoned in tissue sections with lymphomatous proliferation. On the other hand, the chemokine CXCL12 was found to be selectively up-regulated in areas of malignant lymphocytic infiltrations, mostly by ductal epithelial cells and-in an autocrine way-by malignant B cells. These findings raise the possibility that increased production of B cell attracting chemokines by resident and infiltrating cells may contribute to the accumulation and subsequent constant stimulation of memory B-lymphocytes. The shift in the chemokine profile in the involved tissue may form a basis for the selective glandular retention of malignant $B$ cells, thereby increasing the chance of a sustained malignant proliferation.

\section{Summary}

The evolution of lymphoma in SS is a result of a multi-step process that starts as focal mixed cellular infiltrations of the involved glands, most importantly the salivary glands, gradually leading to tissue injury and the appearance of symptoms of exocrine insufficiency. In many SS cases this glandular cellular infiltration progresses through the compartmentalisation of the lymphoid cellular elements to ectopic germinal centre formation and increasing polyclonal B cell hyperactivity. These patients often have high levels of serum IgG, and most of them are anti-Ro/SSA and/or-La/SSB, as well as rheumatoid factor positive. Due to further, poorly understood steps, probably driven by changes in the local chemokine and cytokine milieu and genetic aberrations, monoclonal B cell lines arise that generally produce monoclonal immunoglobulins of rheumatoid factor activity and cryoprotein characteristics. The type II or, less often, type III cryoglobulinaemia leads to the typical immunecomplex-mediated symptoms of vasculitis, inflammatory neuropathy, immune-cytopenia and, occasionally, immune-complex mediated glomerulonephritis. These patients typically have low C4 levels, are cryoglobuline-positive, and occasionally monoclonal paraproteins can be detected in the serum or monoclonal light chains in the urine. The increasing lymphoproliferation causes parotidomegaly or lymphadenopathy. Further alterations in these highly proliferative monoclonal Blymphocyte clones, probably involving the dysfunction of cell-cycle regulation, eventually lead to malignant proliferation, and the clinical picture of an NHL. The better understanding of this clinico-pathologic scenario may help clinicians to identify SS patients, who are at an increased risk of NHL development.

The careful follow-up and regular assessment of serum immunoelectrophoresis, cryoglobuline assay, urinary free light chain assay and thorough physical and instrumental examinations of the relevant exocrine glands, lymphatic glands and all the locations of a potential lymphoma aid to identify SS patients with NHL in an early stage and give ground to initiate therapeutic interventions prior to the propagation of the disease.

\section{Take-home messages}

- Non-Hodgkin's B cell lymphoma develops in 5\% of SS patients.

- Parotidomegaly, neuropathy, vasculitis, lymphadenopathy, cryoglobulinaemia and monoclonal paraproteinaemia are predictive of lymphoma development.

- Lymphoma usually arises at extranodal sites as a result of ectopic lymphoid tissue formation and antigen-driven hyperproliferation of rheumatoid factor-secreting B cells.

- B-lymphocyte activating factor is presumably an important factor in the stimulation of B-lymphocyte proliferation.

- Over-expression of B-lymphocyte attracting chemokines may contribute to the glandular retention of malignant B cells.

\section{References}

[1] Lazarus MN, Robinson D, Mak V, Moller H, Isenberg DA. Incidence of cancer in a cohort of patients with primary Sjögren's syndrome. Rheumatology 2006;45:1012-5.

[2] Kassan SS, Thomas TL, Moutsopoulos HM, Hoover R, Kimberly RP, Budman DR, et al. Increased risk of lymphoma in sicca syndrome. Ann Intern Med 1978;89: 888-92.

[3] Vinagre F, Santos MJ, Prata A, Canas da Silva J, Santos AI. Assessment of salivary gland function in Sjögren's syndrome: the role of salivary gland scintigraphy. Autoimm Rev 2009;8:672-6.

[4] Kauppi M, Pukkala E, Isomaki H. Elevated incidence of hematologic malignancies in patients with Sjögren's syndrome compared with patients with rheumatoid arthritis (Finland). Cancer Causes Control 1997;8:201-4.

[5] Anderson LA, Gadalla S, Morton LM, Landgren O, Pfeiffer R, Warren JL, et al. Population-based study of autoimmune conditions and the risk of specific lymphoid malignancies. Int J Cancer, doi: 10.1002/ijc.24287.

[6] Voulgarelis M, Dafni UG, Isenberg DA, Moutsopoulos H. Malignant lymphoma in primary Sjögren's syndrome. A multicenter, retrospective, clinical study by the European Concerted Action of Sjögren's syndrome. Arthritis Rheum 1999;42: 1765-72.

[7] Pariente D, Anaya JM, Combe B, Jorgensen C, Emberger JM, Rossi JF, et al. NonHodgkin's lymphoma associated with primary Sjögren's syndrome. Eur J Med 1992;1: 337-42.

[8] Sutcliffe N, Inanc M, Speight P, Isenberg D. Predictors of lymphoma development in primary Sjögren's syndrome. Semin Arthritis Rheum 1998;28:80-7.

[9] Royer BD, Cazals-Hatem J, Sibilila F, Agbalika JM, Cayuela T, Sossi F, et al. Lymphomas in patients with Sjögren's syndrome are marginal zone B cell neoplasms, arise in diverse extranodal and nodal sites, and are not associated with viruses. Blood 1997;90:766-75.

[10] Skopouli FN, Dafni U, Ioannidis JPA, Moutsopoulos HM. Clinical evolution, and morbidity and mortality of primary Sjögren's syndrome. Semin Arthritis Rheum 2000;29:296-304.

[11] Tzioufas AG, Boumba DS, Skopouli FN, Moutsopoulos HM. Mixed monoclonal cryoglobulinaemia and monoclonal rheumatoid factor cross-reactive idiotypes as predictive factors for the development of lymphoma in primary Sjögren's syndrome. Arthritis Rheum 1996;39:767-72.

[12] Bombardieri M, Barone F, Humby F, Kelly S, McGurk M, Morgan P, et al. Acitvationinduced cytidine deaminase expression in follicular dendritic cell networks and interfollicular large B cells supports functionality of ectopic lymphoid neogenesis in autoimmune sialoadenitis and MALT lymphoma in Sjögren's syndrome. J Immunol 2007:179:4929-38

[13] Bahler DW, Swerdlow SH. Clonal salivary gland infiltrates associated with myoepithelial sialadenitis (Sjögren's syndrome) begin as non-malignant antigen-selected expansions. Blood 1998;91:1864-72.

[14] Streubel B, Huber D, Wöhrer S, Chott A, Raderer M. Frequency of chromosomal aberrations involving MALT1 in mucosa-associated lymphoid tissue lymphoma in patients with Sjögren's syndrome. Clin Cancer Res 2004;10:476-80.

[15] Tapinos NI, Polihronis M, Moutsopoulos HM. Lymphoma development in Sjögren's syndrome. Novel p53 mutations. Arthritis Rheum 1999;42:1466-72.

[16] Katsikis PD, Youinou PY, Galanopoulou V, Papadopoulos NM, Tzioufas AG, Moutsopoulos HM. Monoclonal process in primary Sjögren's syndrome and cross-reactive idiotype associated with rheumatoid factor. Clin Exp Immunol 1990;82:509-14.

[17] Bahler D, Miklos JA, Swerdlow SH. Ongoing Ig gene hypermutation in salivary gland mucosa-associated lymphoid tissue-type lymphomas. Blood 1997;89: 3335-44.

[18] Daridon C, Youinou P, Pers JO. BAFF, APRIL, TWE-PRIL: Who's who? Autoimm Rev 2008;7:267-73

[19] Groom J, Kalled SL, Cutler AH, Olson C, Woodcock SA, Schneider P, et al. Association of BAFF/BLys overexpression and altered B cell differentiation with Sjögren's syndrome. J Clin Invest 2002;109:59-66.

[20] Lavie F, Miceli-Richard C, Quillard J, Roux S, Leclerc P, Mariette X. Expression of BAFF (BLyS) in T cell infiltrating labial salivary glands from patients with Sjögren's syndrome. J Pathol 2004;202:496-502. 
[21] Jonsson MV, Szodoray P, Jellestad S, Jonsson R, Skarstein K. Association between circulating levels of the novel TNF family members APRIL and BAFF and lymphoid organization in primary Sjögren's syndrome. J Clin Immunol 2005;25:189-201.

[22] Szodoray P, Alex P, Jonsson MV, Knowlton N, Dozmorov I, Nakken B, et al. Distinct profiles of Sjögren's syndrome patients with ectopic salivary gland germinal centers revealed by serum cytokines and BAFF. Clin Immunol 2005;117:168-76.

[23] Novak AJ, Grote DM, Stenson M, Ziesmer SC, Witzig TE, Habermann TM, et al. Expression of BLyS and its receptors in B-cell non-Hodgkin's lymphoma: correlation with disease activity and patient outcome. Blood 2004;104:2247-53.

[24] Ohlsson M, Szodoray P, Loro LL, Johannessen AC, Jonsson R. CD40, CD154, Bax and Bcl-2 expression in Sjögren's syndrome salivary glands: a putative anti-apoptotic role during its effector phases. Scand J Immunol 2002:56:561-71.

[25] De Vita S, Quartuccio L, Fabris L. Hepatitis C virus infection, mixed cryoglobulinemia and BLyS upregulation: targeting the infectious trigger, the autoimmune response, or both? Autoimm Rev 2008;8:95-9.

[26] Ceribelli A, Cavazzana I, Cattaneo R, Franceschini F. Hepatitis C virus infection and primary Sjögren's syndrome. A clinical and serologic description of 9 patients. Autoimm Rev 2008;8:92-4

[27] Marcos M, Alvarez F, Brito-Zerón P, Bove A, Perez-De-Lis M, Diaz-Lagares C, et al. Chronic hepatitis B virus infection in Sjögren's syndrome. Prevalence and clinical significance in 603 patients. Autoimm Rev 2009;8:616-20.

[28] Doria A, Zampieri S, Sarzi-Puttini P. Exploring the complex relationships between infections and autoimmunity. Autoimm Rev 2008;8:89-91.

[29] Yamada T, Zhang K, Yamada A, Zhu D, Saxon A. B lymphocyte stimulator activates p38 mitogen-activated protein kinase in human Ig class switch recombination. Am J Respir Cell Mol Biol 2005;32:388-94.

[30] Guzman Moreno R. B cell depletion in autoimmune diseases. Advances in autoimmunity. Autoimm Rev 2009;8:585-90.

[31] Quartuccio L, Fabris M, Moretti M, Barone F, Bombardieri M, Rupolo M, et al. Resistance to rituximab therapy and local BAFF overexpression in Sjögren's syndrome-related myoepithelial sialadenitis and low-grade parotid B-cell lymphoma. Open Rheum J 2008;2:38-423.

[32] Cornec D, Avouac J, Youinou P, Saraux A. Critical analysis of rituximab-induced serological changes in connective tissue diseases. Autoimm Rev 2009;9:515-9.

[33] Barten M, Fletcher C, Ng LG, Groom J, Wheway J, Laabi Y, et al. TNF deficiency fails to protect BAFF transgenic mice against autoimmunity and reveals a predisposition to B cell lymphoma. J Immunol 2004;172:812-22.

[34] Xu LG, Shu HB. TNFR-associated factor-3 is associated with BAFF-R and negatively regulates BAFF-R-mediated NF-kappa B activation and IL-10 production. J Immunol 2004;169:6883-9.

[35] Villarreal GM, Alcocer-Varela J, Llorente L. Differential interleukin (IL)-10 and IL-13 gene expression in vivo in salivary glands and peripheral blood mononuclear cells from patients with primary Sjögren's syndrome. Immunol Lett 1996;49:105-9.

[36] De Vita S, Dolcetti R, Ferraccioli G, Pivetta B, De Re V, Gloghini A, et al. Local cytokine expression in the progression toward B cell malignancy in Sjögren's syndrome. J Rheumatol 1995;22:1674-80.

[37] Mitsias DI, Tzioufas AG, Veiopoulou C, Zintzaras E, Tassios IK, Kogopoulou O, et al. The Th1/Th2 cytokine balance changes with the progress of the immunopathological lesion of Sjogren's syndrome. Clin Exp Immunol 2002;128:562-8.

[38] Hansen A, Odendahl M, Reiter K, Jacobi AM, Feist E, Scholze J, et al. Diminished peripheral blood memory B cells and accumulation of memory B cells in the salivary glands of patients with Sjögren's syndrome. Arthritis Rheum 2002;46: 2160-71.

[39] Jacobi AM, Odendahl M, et al. Correlation between circulating CD27high plasma cells and disease activity in patients with systemic lupus erythematosus. Arthritis Rheum 2003;48:1332-42.

[40] Barone F, Bombardieri M, Rosado MM, Morgan PR, Challacombe SJ, De Vita S, et al. CXCL13, CCL21, and CXCL12 expression in salivary glands of patients with Sjögren's syndrome and MALT lymphoma: association with reactive and malignant areas of lymphoid organization. J Immunol 2008;180:5130-40.

\section{Frequency and determinants of flare and persistently active disease in systemic lupus erythematosus}

Selection of flare as the primary outcome variable in systemic lupus erythematosus (SLE) clinical trials fails to capture patients with persistently active disease (PAD). Here, Nikpour M. et al. (Arthritis Rheum 2009; 61: 1152-8) sought to elucidate the frequency and determinants of flare and PAD. Prospectively collected data from the Toronto Lupus Cohort were used to determine the incidence of flare and PAD in 2004 and 2005. Flare was defined as an increase in SLE Disease Activity Index 2000 update (SLEDAI-2K) score of $>/=4$ from the previous visit. PAD was defined as a SLEDAI-2K score of $>/=4$, excluding serology alone, on $>/=2$ consecutive visits. Data from 1,2 , and 3 years prior were used to model flare and PAD in 2004. Model properties were tested for prediction of flare and PAD in 2005. One-third of the patients had $>/=1$ flare, whereas nearly half experienced PAD in a given year. Nearly $60 \%$ of the patients had episodes of flare or PAD per year. At least $25 \%$ of patients had PAD without achieving the definition of flare. In the best-fitting model, predictors of PAD in 2004 were SLEDAI-2K score at the start of the outcome interval and prior cutaneous or musculoskeletal disease activity. This model gave $79 \%$ correct prediction of PAD in 2005. In contrast, flare prediction models performed poorly. Thus, persistent activity is a common disease state in SLE and should be an outcome variable in SLE clinical trials. PAD prediction model may aid prognostication and selection of patients for inclusion in clinical trials.

\section{Functional TLR9 modulates bone marrow B cells from rheumatoid arthritis}

TLR9 recognizes unmethylated CpG-rich, pathogen-derived DNA sequences and represents the component of the innate immune system that heavily influences adaptive immunity and may contribute to the immunological disturbances in rheumatoid arthritis (RA). Accumulating data indicate that BM of RA patients participates in the pathogenesis of this disease as a site of pro-inflammatory cytokines overproduction and lymphocytes activation. Here, Rudincka W. et al ( Eur J Immunol 2009; 39: 1211-20), investigated the functionality of TLR9 and its role in the modulation of RA BM B-cell functions. The authors report that BM B cells isolated from RA patients express TLR9 at the mRNA and protein levels acquired at the stage of preB/immature B-cell maturation. Stimulation of BM CD20 + B cells by CpG-containing oligodeoxynucleotide-enhanced expression of activation markers (CD86 and CD54) triggered IL-6 and TNF-alpha secretion and cell proliferation. Significantly higher levels of eubacterial DNA encoding 16S-rRNA were found in BM samples from RA than osteoarthritis patients. Moreover, RA BM B cells exerted higher expression of CD86 than their osteoarthritis counterparts, suggesting their in situ activation via TLR9. This data indicates that TLR9 may participate in direct activation and proliferation of B cells in BM, and therefore could play a role in the pathogenesis of RA.

\section{Selective regulation of autoreactive B cells by FcgammaRIIB}

FcgammaRIIB is an inhibitory receptor which plays a role in limiting B cell and dendritic cell (DC) activation. Since FcgammaRIIB is known to dampen the signaling strength of the BCR, Venkatesh J. et al. (J Autoimmun 2009; 32: 149-57) wished to determine the impact of Fcgamma RIIB on the regulation of BCRs which differ in their affinity for DNA. For these studies, FcgammaRIIB deficient BALB/c mice were bred with mice expressing the transgene-encoded $\mathrm{H}$ chain of the R4A anti-DNA antibody which gives rise to BCRs which express high, low or no affinity for DNA. The detection of FcgammaRIIB in R4A BALB/c mice led to an alteration in the B cell repertoire, allowing for the expansion and activation of high affinity DNA-reactive B cells. By 6-8 months of age, R4A x FcgammaRIIB -/-BALB/c mice spontaneously developed anti-DNA antibody titers. These mice also displayed an induction of IFN-inducible genes and an elevation in levels of the B cell survival factor, BAFF. These data demonstrate that FCgammaRIIB preferentially limits activation of high affinity autoreactive B cells and can influence the activation of DC through an immune complex-mediated mechanism. 